DOI: $10.13037 /$ ci.vol20n44.5470

\title{
Dramas televisivos de prestígio e masculinidade
}

PRESTIGE TELEVISION DRAMAS AND MASCULINITY

\section{Mayka Castellano ${ }^{1}$}

ORCID: http://orcid.org/0000-0003-4401-5979)

(Universidade Federal Fluminense, Programa de Pós-Graduação em Comunicação, Niterói - RJ, Brasil)

Melina Meimaridis ${ }^{2}$

ORCID: https://orcid.org/0000-0003-3481-817X

(Universidade Federal Fluminense, Programa de Pós-Graduação em Comunicação, Niterói - RJ, Brasil)

\section{Gabriel Ferreirinho ${ }^{3}$}

ORCID: https://orcid.org/0000-0002-1607-9142

(Universidade Federal Fluminense, Programa de Pós-Graduação em Comunicação, Niterói - RJ, Brasil) 
Resumo

$\mathrm{O}$ artigo analisa as controvérsias de gênero ligadas

à discussão sobre "qualidade televisiva" e "dramas de prestígio" em séries americanas. A categoria "TV de qualidade" já sofreu inúmeras mudanças, porém, indicamos como significativa a predominância de obras criadas por homens, com protagonistas masculinos e que possuem códigos pertencentes ao universo da masculinidade hegemônica apontadas como paradigmáticas do atual bom momento vivido pela televisão estadunidense. Conclui-se, portanto, que é no mínimo problemática a associação de ideias como "complexidade", "qualidade" e "prestígio" com a representação da masculinidade hegemônica em produtos televisivos populares.

Palavras-chave: Séries. Masculinidade. TV de qualidade.

\section{Abstract}

This article analyzes the gender controversies linked to the discussion about "quality television" and "prestigious dramas" in American series. The "Quality TV" category has undergone numerous changes; however, we indicate as significant the predominance of series created by men, with male protagonists and that use codes belonging to the hegemonic masculine universe being held as paradigmatic of the present prosperous moment lived by the American television. Leading off from the assumption that it is problematic to associate certain ideas like "complexity", "quality" and "prestige" with the representation of hegemonic masculinity in popular television products.

Keywords: Series. Masculinity. Quality TV.

\section{Introdução}

Pormuito tempo considerada ummeio inferior, sobretudo por suanaturezaindustrial, a televisão vive, desde o início dos anos 2000, uma nova Era de Ouro, proporcionada em grande parte por sua prolífica produção de séries ficcionais, com destaque para a pujante indústria estadunidense. Recentemente, séries como The Sopranos (HBO, 19992007), Mad Men (AMC, 2007-2015) e Breaking Bad (AMC, 2008-2013) passaram a ser percebidas como obras de arte prestigiosas, louvadas pelo público e pela crítica por uma estética elevada e distintiva qualidade narrativa. Embora possamos perceber a atribuição de valor aos artefatos oriundos da indústria da TV como um avanço, entendemos que a categorização de determinadas obras como detentoras de "qualidade" não ocorre sem problemas, uma vez que as produções identificadas como paradigmáticas deste momento não só deixam de fora uma série de elementos típicos da gramática televisiva, como são, sintomaticamente, criadas por homens, com protagonistas masculinos e códigos pertencentes ao universo da masculinidade. Nesse sentido, o presente artigo busca analisar as controvérsias de gênero ligadas à discussão sobre "qualidade televisiva" e "dramas de prestígio". 
Se hoje apontamos com relativa facilidade a vinculação entre produtos televisivos e qualidade artística, é importante destacar que esse é um dado novo. Por conta de sua natureza comercial, as narrativas ficcionais seriadas foram, por décadas, consideradas produtos muito "industriais", frutos de uma lógica produtiva em que séries de êxito eram replicadas reiteradamente como numa linha de produção. As séries, dessa forma, eram elaboradas por meio de modelos pré-estabelecidos, fórmulas de sucesso que renderiam grandes audiências para as emissoras (GITLIN, 1994). Para os críticos da indústria cultural, tal padronização da produção narrativa promoveria uma perda dos elementos fundamentais às obras artísticas, como "originalidade" e "autenticidade". Contudo, nas últimas décadas, as séries americanas têm investido em múltiplas estratégias como forma de se distanciarem dessa imagem "industrial", buscando investir na produção, no roteiro e, também, no aprimoramento estético.

A atribuição de um status de "qualidade" a determinadas séries televisivas não é um fenômeno novo, muito menos uniforme em seus critérios. Avaliar a "qualidade" de uma obra audiovisual é sempre uma tarefa difícil, visto que análises estéticas frequentemente perpassam questões de gosto (MCCABE; AKASS, 2007; BOURDIEU, 2007). É necessário ressaltar, nesse ponto, que este artigo não tem a ambição de indicar suas próprias definições para a "televisão de qualidade", categoria que consideramos profundamente complexa, apenas utilizaremos o rótulo já proposto por teóricos, e adotado pela imprensa especializada, como um ponto de partida para nossa reflexão sobre a relação dessa distinção com a questão de gênero. Mais precisamente, utilizaremos as contribuições de Jane Feuer (1984), Robert Thompson (1996), Paola Brembilla e Lucia Tralli (2015), Felipe Muanis (2015) e Michael Newman (2016).

No cerne da discussão que envolve "qualidade" televisiva, encontramos uma série de elementos associados a uma forte presença masculina. A televisão e suas produções já despertam, há décadas, grande interesse acadêmico em pesquisas dedicadas ao debate de gênero. Inicialmente, as investigações se mantiveram centradas nas representações da feminilidade e nos papéis desempenhados por mulheres na tela (RABINOVITZ, 1989; DAVIS, 1990). Tal foco está diretamente relacionado à domesticidade atrelada ao meio televisivo, que na década de 1950 visava sobretudo ao público feminino, responsável pela economia doméstica, e à influência da segunda onda do movimento feminista, que incentivou sobremaneira o olhar acadêmico e intelectual sobre as representações da mulher em diversos artefatos culturais (SPIGEL, 1989; FEASEY, 2008; CASTELLANO; MEIMARIDIS, 2018). Apesar disso, há ainda uma lacuna nos estudos dedicados à 
relação entre identidade de gênero e televisão, uma vez que, embora exista uma robusta produção intelectual acerca das representações da mulher e do feminino na televisão americana (DOW, 2005; LOTZ, 2006; CASTELLANO; MEIMARIDIS, 2018), o campo da masculinidade permanece relativamente inexplorado.

Uma consequência grave da supressão do homem como objeto de estudo, como sexo e gênero, é que, dessa forma, assume-se a ideia do homem como o "sujeito universal", imprime-se a noção de que a masculinidade é resoluta e constante, não passível de crítica e indagação; fixa-se o sexo masculino e a heterossexualidade como estável e inalterável, base para a observação de "outras" categorias (entendidas sempre a partir da ideia da justaposição a esse referencial inabalável), e não como parte do grande escopo do que é a sexualidade (em relação a sexo, gênero e orientação sexual). A ideia que subjaz nesse fenômeno é a de que as discussões sobre gênero devem sempre girar em torno das problemáticas associadas ao feminino, fenômeno semelhante à falsa percepção de que as discussões sobre raça devem endereçar sempre o sujeito negro, a partir da equivocada (e racista) noção de que o indivíduo branco não é racializado, pairando sobre as análises como o sujeito por excelência, e sobre o qual não é necessário falar (RIBEIRO, 2017). Dessa forma, é curioso (e sintomático) que, embora as séries que integrem esse grupo distinto de produções aduladas sejam marcadamente masculinas, esse é um dado que costuma ser ignorado na apresentação das tramas, tanto pela crítica quanto pelo público, que não costuma defini-las como séries "de homenzinho", em contraposição às séries protagonizadas por mulheres, que costumam ser rotuladas, de forma pejorativa, como endereçadas particularmente ao público feminino ${ }^{1}$.

Com isso posto, na presente discussão analisamos o contexto em que um determinado tipo de prestígio é atribuído às séries produzidas durante a chamada terceira Era de Ouro da televisão americana, com foco na complexa relação estabelecida entre a ideia de "qualidade" e a masculinidade, seja a partir da verificação da forte presença masculina por trás das câmeras, seja na identificação do homem como eixo central das narrativas.

\footnotetext{
${ }^{1} \mathrm{O}$ mesmo tipo de raciocínio pode ser endereçado à questão racial. Em Master of None, Aziz Ansari, ator e roteirista de ascendência indiana, interpreta o personagem Dev, um ator que vive às voltas com testes de elenco. No quarto episódio da primeira temporada, intitulado "Indianos na TV", dedicado justamente ao tema da representação, Dev faz um teste para uma nova série de TV e descobre que um amigo seu, igualmente de ascendência indiana, também está concorrendo a um papel na mesma produção. Em conversa com um produtor da série, Dev constata que ele e o amigo não poderão entrar, juntos, para o elenco. Depois de perguntar: "Por que não pode haver dois indianos em uma série?", Dev ouve do homem (branco) responsável pelo projeto: "Vou ser franco com você. Se eu fizer uma série com dois indianos no pôster, todos vão achar que é uma série indiana". Curiosamente, ninguém parece se referir a Breaking Bad ou Mad Men como séries brancas.
} 


\section{Os meandros da qualidade televisiva}

A noção "televisão de qualidade" recebeu diferentes acepções ao longo da trajetória do meio nos Estados Unidos. Uma das principais abordagens a esse debate aparece na tentativa de periodização das produções encerrada no termo Golden ages of Television, ou, em português, Eras de Ouro da televisão ${ }^{2}$. Nessa categorização, um grupo limitado de produções é destacado como superior ao restante da programação televisiva. A Primeira Era de Ouro, ocorrida entre o final da década de 1940 e início dos anos 1960, foi um período marcado pela percepção de que "pessoas sérias podiam levar a TV a sério" (THOMPSON, 1996, p.11), sobretudo por conta do elevado número de adaptações literárias e teatrais que eram exibidas, como The Actors' Studio (ABC/CBS, 1948-1950). A qualidade, assim, vinha da associação das obras televisivas com formas de arte já legitimadas. Embora muitos pesquisadores concordem com a premissa de que as produções do período eram “de qualidade”, para Robert Thompson (1996) o termo só seria corretamente aplicado na década de 1980, com a Segunda Era de Ouro, composta por dramas como Hill Street Blues (NBC, 1981-1987) e Cagney and Lacey (CBS, 19811988).

O conceito "TV de Qualidade" aparece inicialmente no livro MTM: Quality Television (FEUER; KERR; VAHIMAGI, 1984), em que os autores indicam as produções da empresa MTM Enterprises como detentoras de um "fator de qualidade". A produtora, criada pela atriz Mary Tyler Moore e seu então marido Grant Tinker, em 1969, apostava em um público jovem, urbano e com renda disponível (BREMBILLA; TRALLI, 2015). Para Feuer (1984), a empresa dava mais liberdade para as equipes criativas e seus programas podiam ser considerados "liberais" e "sofisticados", o que era justificado pela percepção das emissoras sobre os potenciais lucros advindos com a captura de uma parcela específica de espectadores, em vez de uma maior quantidade de público com indicadores demográficos variados. Tal situação era particularmente interessante aos patrocinadores, de olho sobretudo nos "moradores afluentes de áreas urbanas entre a faixa etária de 18 a 49 anos" (NEWMAN, 2016, s/p).

Em busca dessa fatia do mercado, as empresas, segundo Newman (2016), começaram a adotar um teor "progressista", sobretudo no horário nobre, com uma maior representação de minorias e uma programação mais urbana e dita "relevante". É nesse

${ }^{2}$ A exata duração de cada Era de Ouro da televisão americana ainda é debatida por pesquisadores de televisão, mas entende-se que primeira golden age se refere aproximadamente ao período entre 1947 a 1960, a segunda entre 1981 a 1998, a terceira a partir de 1999. 
momento que Michael Schudson (1995) afirma ter ocorrido a "noticialização da cultura popular", em que a programação televisiva, principalmente as séries ficcionais, começam a abordar questões políticas e sociais em seus enredos.

Não foi somente no aspecto social que a "TV de qualidade" inovou, mas, também, na narrativa, ao apresentar tramas mais serializadas com arcos que se desenvolviam ao longo das temporadas. Ao analisar Hill Street Blues, Thompson dá pistas sobre o que tornaria uma produção digna de receber o selo de "qualidade": a produção "era literária, visualmente densa e preenchida com uma linguagem que parecia mais com o cinema do que com a televisão" (1996, p.38, tradução nossa), algo, segundo ele, nunca visto na TV. Novamente, observamos uma espécie de "prestígio vicário" (CASTELLANO; MEIMARIDIS, 2016), traduzido no esforço em indicar a qualidade atrelada a uma "não televisão", ou seja, a obras que fugissem das normas narrativas e estéticas tradicionalmente associadas ao meio televisivo. O público associado a essa "não televisão", observa Newman, "geralmente é mais masculino, adulto e sofisticado em comparação com aqueles associados com a televisão comum, concebida como cultura de massa feminizada, endereçada ao menor denominador comum" (2016, s/p).

A necessidade que o meio televisivo tem de reproduzir fórmulas de sucesso levou ao aumento, na década de 1990 e início dos anos 2000, de dramas médicos e policiais que se assemelhavam às aclamadas St. Elsewhere e Hill Street Blues. Logo, a televisão estava repleta de produções que se encaixavam na estética da "TV de qualidade", mas que haviam perdido a "singularidade" das obras originais. No final da década de 1990 e início dos anos 2000, surgiu um novo modelo valorativo, com as produções The Sopranos e, mais tarde, The Wire (HBO, 2002-2008). Para Barbara Maio (2009), nesse momento, a televisão americana teria entrado na "Terceira Era de Ouro", período em que a "qualidade como uma exceção" se torna "qualidade como regra". Se a HBO se consolidava como a portadora do prestígio à época, é interessante notar que a primeira série do canal a conquistar o público tenha sido Sex and the City (HBO, 1998-2004), produção protagonizada por quatro amigas e que contava as desventuras de mulheres adultas em Nova York, um marco na representação cultural do chamado pós-feminismo (MESSA, 2006). Embora tenha sido responsável por aumentar significativamente o número de assinantes do canal, a atração raramente é apontada como o início da nova safra de ouro, título que costuma ficar com The Sopranos, que estreia um ano depois, uma série com um tom bastante masculino, sobre a qual discorreremos mais à frente. 
A terceira Era de Ouro não viu apenas o aumento significativo no número de obras de "qualidade", mas, também, o surgimento de outra categoria intitulada "televisão de prestígio", com dramas como Game of Thrones (HBO, 2011-Presente) e The Americans (Showtime, 2013-Presente) recebendo o título de "produções sérias" pelos críticos (ALSOP, 2015; ROSENBERG, 2016). Apesar da recente popularização do termo drama de prestigio, a categoria já existiu no passado, nas décadas de 1950 e 1960, para se referir a "peças contemporâneas, clássicas ou excepcionais adaptadas para a televisão" (BAILEY, 1970 , p. 329, tradução nossa). Recentemente, a categoria, ainda usada principalmente por críticos de televisão e pouco debatida pela academia, está relacionada a produções, principalmente de canais premium ${ }^{3}$ e veículos de streaming, que se distanciam da estética ou narrativa tradicionalmente associadas ao meio televisivo. O "drama de prestígio", assim como a "televisão de qualidade" da década de 1980, se distingue ao se afastar do costumeiro ethos televisivo, com produções esmeradas, maior complexidade narrativa (MITTELL, 2006; 2015) e estética cinematográfica. Tal associação direta entre essas obras televisivas e meios mais valorizados fica evidente em uma matéria dedicada a listar os 13 elementos essenciais de um drama de prestígio ${ }^{4}$, publicada no site Vulture, em que os dois principais elementos identificados são: "1) É como um romance"; “2) É como um filme".

Embora os críticos televisivos se esmerem ao atribuir o selo "drama de prestígio" a determinadas produções, elaborando seus próprios critérios avaliativos, chama a atenção o nono item da supracitada lista: "homens tristes". De acordo com o site, séries dignas de serem levadas a sério "são provavelmente sobre homens de meia idade, provavelmente brancos, falhos e que estão apenas lutando para viver suas vidas no mundo" (tradução nossa). Não é difícil observar, de fato a predominância desse tipo de protagonista nas tramas que arregimentam sucesso de público e crítica desde a virada dos anos 2000. Para compreendermos como essa relação se estabeleceu, a ponto de naturalizarmos a relação entre seriedade, qualidade e jornadas de homens (brancos, heterossexuais) problemáticos, é necessário que debatamos, primeiro, as representações dominantes sobre o masculino.

\footnotetext{
${ }^{3}$ A televisão americana se divide em canais abertos (free-to-air) e canais fechados, basic cable (sem assinatura mensal) e premium cable (com assinatura mensal).

${ }^{4}$ Disponível em: http://www.vulture.com/2017/03/prestige-tv-signs-youre-watching.html. Acesso em:
} 


\section{A construção da masculinidade hegemônica}

As séries de televisão são produções que nos permitem analisar construções discursivas participantes na elaboração do imaginário social sobre as identidades. Através de um eterno processo de reconfiguração (RICOEUR, 1994), se estabelece uma interlocução entre as identificações de gênero individuais e as representações e formas de ver o mundo que nos são apresentadas a partir de manifestações culturais. As concepções de masculinidade também são elaboradas por meio das identificações com narrativas, pessoas e personagens que conhecemos pela televisão. Como a construção de gênero é histórica e praticada discursivamente, é possível apontarmos uma relação contemporânea com concepções de masculinidade que remetem desde a antiguidade clássica até atributos mais modernos. Como Danielle Brasiliense e Pedro Ansel (2017) propõem, precisamos perceber que certos discursos ordenadores, mesmo que proferidos na Grécia Antiga, mantêm relação com as formações discursivas contemporâneas.

Ainda mais estrutural, a falta de atenção às masculinidades e suas representações, mencionada na introdução deste artigo, compactua com a manutenção de espaços de poder políticos e culturais ocupados por homens há milênios. Connell (2005) é extremamente enfática ao apontar que a política pública é masculina; há uma predominância de homens ocupando cargos em todas as instâncias de poder e as mulheres que conseguem ultrapassar essa barreira o fazem geralmente a partir das redes de contato com homens, não com mulheres. Além disso, é comum que homens se mantenham no poder indicando novos líderes, sucessores, aliados, criando pressupostos arbitrários que favorecem outros homens, ou exigindo qualificações técnicas e experiências inacessíveis às mulheres. Tal situação pode ser facilmente enxergada no universo da produção audiovisual estadunidense, dominada por executivos, roteiristas e diretores homens, alguns deles alvos de recentes denúncias sobre abusos e intimidações apresentadas por atrizes e demais profissionais do ramo 5 .

No campo das representações, podemos perceber uma celebração de códigos das masculinidades atuando constantemente no sentido da masculinidade hegemônica (CONNELL, 2005). Connell (2005) entende o conceito de hegemonia a partir de suas leituras das relações de classe propostas por Gramsci, em que a manutenção de poder por

\footnotetext{
${ }_{5}^{5}$ Recentemente, ganhou destaque o movimento "Time's up", que além de dar assistência legal às mulheres na prevenção e denúncia de assédio sexual, chama a atenção para o desequilíbrio de gênero no ambiente de trabalho. O movimento ganhou visibilidade a partir da adesão de celebridades em premiações importantes no início de 2018, como o Emmy e o Oscar.
} 
determinados grupos está circunscrita, também, às dinâmicas culturais. Como diversas culturas, em diferentes tempos, podem exaltar uma masculinidade em detrimento de outras, o conceito de masculinidade hegemônica vai concernir às configurações de práticas de gênero que sustentam as questões de legitimidade do patriarcado, que garantem (ou operam no sentido de garantir) o lugar de dominação aos homens e de subordinação às mulheres. O que não quer dizer que todas as masculinidades estejam inseridas (apesar de todos os homens serem beneficiados por essa lógica) ou que tais indivíduos detentores de poder institucional e/ou grandes fortunas sejam exemplares das normas de gênero em suas vidas pessoais. Ainda assim, o mais comum é que se estabeleça um modelo hegemônico quando esse conflui com o ideal cultural e com o poder institucional: "É a reivindicação bem-sucedida da autoridade, mais do que a violência direta, que é a marca da hegemonia" (CONNELL, 2005, p. 77, tradução nossa).

Entender o que configura as características da masculinidade hegemônica contemporânea é compreender as reconfigurações de masculinidade durante o desenvolvimento dos Estado ocidentais ao longo da Era Moderna e, a partir desse recorte, quatro aspectos são ressaltados pela autora. O primeiro condiz com a transformação cultural que possibilitou novas perspectivas para o entendimento da sexualidade e da individualidade, a partir das cisões com a igreja católica medieval estimulada pelos desdobramentos do Renascimento e das reformas protestantes, que diminuíram o poder regulador da religião nos campos da ciência e da vida cotidiana. No âmbito privado, o foco mais forte passou a se referir às relações conjugais, com o reposicionamento da heterossexualidade matrimonial como o grande exemplo de sexualidade no lugar da simples negação monástica; "A autoridade cultural da heterossexualidade compulsória seguiu claramente essa mudança" (CONNELL, 2005, p. 186, tradução nossa).

Tal processo foi acompanhado de uma nova abordagem sobre as expressões individuais. A ideia de uma relação pessoal, e não mediada, com Deus, serve de base para o desenvolvimento do individualismo e da noção de um ser autônomo. Dessa forma, sendo o masculino uma identidade de gênero ligada à racionalidade e a civilização ocidental a portadora dessa razão (perante um mundo "ignorante"), é forjada uma associação cultural entre a legitimidade do patriarcado e a legitimidade do império (CONNELL, 2005). Um segundo aspecto, segundo autora, está na formação de impérios extracontinentais partindo dos Estados europeus na costa oeste do Atlântico, como Portugal e Espanha, que, ao chegarem a outras partes do mundo, ajudam a difundir suas próprias atribuições de gênero, a partir, por exemplo, da divisão de tarefas executadas por homens e mulheres. O crescimento de cidades que serviam como centros do capitalismo comercial, e geraram 
novas configurações da vida cotidiana - principalmente baseadas numa regulamentação mais consistente e num maior anonimato -é apontado como o terceiro aspecto das reconfigurações de masculinidade na era moderna, apesar de suas implicações na questão de gênero só serem notáveis nos séculos XVII e XVIII.

Por fim, o quarto aspecto colocado por Connell (2005) são as guerras que dominaram a Europa; tanto no que tange às guerras religiosas dos séculos XVI e XVII, quanto às guerras dinásticas dos séculos XVII e XVIII; que, de acordo com a autora, tiveram como efeito também o estremecimento da ordem de gênero, por meio de um Estado centralizado e absoluto, que permitiu a institucionalização do poder masculino num alcance nunca antes visto (CONNELL, 2005).

\section{Uma era masculina}

Após um longo caminho de desenvolvimento, marcado, também, por rupturas e desvios, encontramos atualmente uma ordem de gênero em que a masculinidade no sentido moderno já está estruturada e se apresenta, em síntese, com um caráter individual, definida na oposição com o feminino e institucionalizada na economia e no Estado (CONNELL, 2005). Com isso posto, Kimmel propõe características da masculinidade hegemônica: "é um homem no poder, um homem com poder e um homem de poder. Nós equiparamos a masculinidade com ser forte, bem sucedido, capaz, confiável, no controle" (2004, p. 184). Com algumas adaptações, concernentes sobretudo à ideia de "no controle", esse é o perfil dos protagonistas das séries legitimadas com o selo de "qualidade" na Terceira Era de Ouro. O primeiro dessa linhagem pode ser identificado em Tony Soprano (James Gandolfini) protagonista de The Sopranos. Como já comentamos, a série é particularmente importante por apontar um momento de virada na produção televisiva e constantemente citada como precursora não só da nova era de ouro da TV como do momento em que definitivamente as séries televisivas passam a figurar no panteão das artes sérias.

O protagonista Tony Soprano é um mafioso de Nova Jersey, definido por Martin como "um sujeito velha-guarda - bronco, corporal, capaz de conseguir o que quisesse; uma fantasia sedutora ainda que desconfortável tanto para homens como para mulheres num mundo pós-feminista" (2014, p.111). Embora se alinhe sem grandes problemas ao ideal de masculinidade hegemônica - um homem forte, bruto, heterossexual - conduta referendada pelo seu casamento de longa data e também por suas inúmeras traições, dotado de um bom desempenho profissional (chefiar a máfia local e manter o núcleo familiar 
sob seu domínio), Tony traz também uma característica fundamental aos personagens da terceira era de ouro: uma masculinidade atormentada. Conquanto se esforce em manter os paradigmas hegemônicos, essa manifestação da masculinidade se vê atravessada por outras demandas contemporâneas, dentre elas a estabilidade psíquica, característica do que se convencionou associar à ascensão de uma "cultura terapêutica". De acordo com Furedi (2004), um dos principais sintomas dessa fase pode ser medido pelo uso cada vez mais corrente do vocabulário terapêutico, que deixa de se referir apenas a problemas atípicos e estados mentais exóticos para se tornar corriqueiro em situações do cotidiano, além da frequência e disseminação na população em geral do diagnóstico de transtornos de ordem psíquica. Às voltas com problemas psicológicos, o mafioso é levado a buscar ajuda na terapia e nos medicamentos. O autor cita como bastante sintomático da ascensão desse imaginário o fato de a audiência norte-americana não achar "bizarro" o personagem se consultar frequentemente com sua psiquiatra, Dra. Jennifer Melfi (Lorraine Bracco).

A "bizarrice" dessa situação reside na contradição estabelecida por um mafioso figura que remete a um contexto cultural extremamente masculino, marcado por questões como honra, herança, palavra, em que os problemas costumam ser resolvidos a partir de um código interno que prevê assassinatos e espancamentos, e, sobretudo, um pacto de silêncio - confidenciar suas agruras emocionais a uma mulher e buscar a origem de seus dilemas e mal-estares na relação que mantinha, na infância, com sua mãe. Cabe ressaltar que, a despeito disso, Tony, seus aliados e inimigos não se furtam de recorrer ao modus operandi típico da máfia sempre que necessário.

A linhagem do mafioso foi seguida na televisão por Vic Mackey (Michael Chiklis), um policial durão, porém corrupto do drama The Shield (FX, 2002-2008) e Tommy Gavin (Denis Leary), um bombeiro traumatizado com os eventos de 11 de setembro de Rescue Me (FX, 2004-2011), que se torna alcoólatra e viciado em medicamentos controlados. Ambas as produções focavam em "profissões para os mais machos dos homens - bombeiros e policiais" (MARTIN, 2014, p.111), embora os protagonistas não fossem apresentados como heróis e sim como sujeitos dotados de desvios éticos e psicológicos.

Outra produção aclamada como epítome da terceira era de ouro é Breaking Bad, que acompanha a história de Walter White (Bryan Cranston), mais um homem branco heterossexual de meia idade, professor de Química do ensino médio. A jornada do personagem começa com a descoberta de um câncer terminal. A falta de condições para arcar com os custos do tratamento serve de gota d'água para Walter assumir a mágoa pela falta de reconhecimento profissional e pelo desprestígio diante de seu enorme potencial 
intelectual, fato que o deprime, por não o posicionar em um lugar de força dentro de suas relações sociais. Chegando à conclusão de que não tem mais nada a perder, o professor usa seus conhecimentos para produzir e vender metanfetamina, ponto de partida para uma série de atos moralmente questionáveis. O que a princípio soa como uma tentativa pontual de conseguir recursos se revela, aos poucos, uma trajetória de busca por poder e pela validação de sua masculinidade a partir do olhar hegemônico; o que se dá por meio da violência, do acionamento de hierarquias profissionais e familiares e de uma racionalidade aguda.

A série acompanha a transformação do emasculado, frágil e ressentido professor ao poderoso e temido Heisenberg, seu pseudônimo no tráfico de drogas. É significativo que no início de Breaking Bad o protagonista enfrente diversas dificuldades no relacionamento com sua esposa Skyler (Anna Gunn), que frequentemente assume o papel de chefe da família. No entanto, conforme Walter vai ganhando mais autoridade no mundo do crime, essa postura de dominação começa a se impor também em sua vida pessoal, o que se reflete, por exemplo, em uma melhora em seu desempenho sexual.

Não objetivamos, aqui, apresentar descrições e análises pormenorizadas dessas tramas, o que por si só renderia extensos e profícuos trabalhos. Com esses breves apontamentos sobre duas das séries mais reverenciadas no que se convencionou chamar de Terceira Era de Ouro, pretendemos apenas situar o leitor em nosso principal argumento neste artigo: não é uma coincidência que quase todas as séries consideradas de "qualidade" e "prestígio" (usemos aqui qualquer um dos adjetivos) sejam protagonizadas por homens, com enredos que, através de diferentes alegorias, representam a relação do homem, ou da masculinidade, com a manutenção do poder. O objetivo ao dizer que essas séries incorporam uma masculinidade não é delimitá-la ao gosto dos homens - as identificações e gostos são muito mais complexos do que as dicotomias discursivas usadas no mundo para explicá-los - mas, sim, destacar a reiteração de determinados códigos de uma masculinidade hegemônica.

A centralidade da figura masculina em narrativas consideradas "sérias" e complexas responde, do ponto de vista da representação, a um longo histórico, que esboçamos brevemente, sobre a consolidação da masculinidade hegemônica. A partir do olhar sobre o mercado televisivo, assim como em diversos âmbitos sociais, percebemos uma significativa predominância de profissionais homens também do outro lado da tela, sobretudo em cargos importantes dentro de emissoras e produtoras de conteúdo. Em relação às séries citadas mais pontualmente, ambas têm por trás a figura de um showrunner 
homem (respectivamente David Chase e Vince Gilligan). Em um livro dedicado aos homens dificeis da ficção seriada contemporânea, Martin (2014) junta numa mesma linha de análise criadores e criaturas. Seu argumento é que Tony, Walter e outros personagens complexos que povoam as séries de TV nos dias de hoje são, de alguma forma, imagem e semelhança de homens geniais que assinam seu processo criativo. Nenhuma surpresa, portanto, que durante muito tempo os dramas incensados tivessem como personagem central homens de meia idade, brancos, cisgênero e heterossexuais - o perfil de grande parte dos sujeitos poderosos da televisão americana. Outra forma de olhar para essas criações ficcionais é percebê-las como representações que legitimam práticas de gênero e posicionam esse tipo específico de homem como o sujeito a ser admirado, refletido e almejado. Não são, portanto, apenas homens incríveis elaborando histórias sobre outros homens especiais, mas homens tentando colocar suas identificações e aflições de gênero em um lugar de autoridade a partir das histórias que narram.

Se dentro das tramas elaboradas a presença masculina se tornou evidente, o mesmo pode-se dizer da audiência da televisão nos últimos tempos. Nesse sentido, é significativa a menção já feita neste artigo sobre o processo de masculinização da audiência que acompanhou o crescimento de prestígio do meio televisivo. A percepção, aparentemente verificada por analistas, é de que a televisão foi se tornando "melhor" conforme seu público deixava de ser quase que exclusivamente feminino. A complexidade narrativa e a qualidade técnica passavam a ser apontadas em obras que se distanciavam, cada vez mais, das tradicionais tramas melodramáticas, típicas de um gosto associado ao universo feminino. Não tardou para, no senso comum, e, também, na crítica, embora muitas vezes de forma velada, se estabelecesse a noção de que uma ficção seriada seria melhor na medida em que se afastasse da ideia de uma produção "de mulherzinha". Um tipo de caracterização amiúde usado para rebaixar uma série de artefatos culturais.

A associação entre a massa e as mulheres é bastante antiga. Textos clássicos das ciências sociais e da psicologia desde o século XIX buscam estabelecer essa relação a partir da controversa ideia da multidão como um fenômeno social com características femininas, tais como a irracionalidade e a volubilidade, ideia comum no pensamento intelectual da época (LE BON, 1905). Aplicada ao tratamento específico da cultura, tal noção ajudou a embasar a supracitada categorização dos produtos voltados ao público feminino como intrinsicamente inferiores.

No texto A cultura de massa enquanto mulher - o “outro" do Modernismo, Andreas Huyssen (1996) aborda essa questão partindo da análise de um dos livros fundadores 
do Modernismo: Madame Bovary (1856), de Gustave Flaubert. Apoiado em obras de autoras feministas, Huyssen desconstrói a famosa frase de Flaubert, "Madame Bovary c'est moi" ("Madame Bovary sou eu"), para mostrar que essa identificação do autor com uma possível feminilidade imaginária tinha estreita relação com a posição cada vez mais marginal que a produção artística ocupava em um contexto de valorização da razão, do progresso, dos negócios, da ciência, da indústria... Em um ambiente hostil a domínios como a literatura e as artes, fazia sentido o autor reivindicar uma proximidade com o universo feminino. Ao mesmo tempo, essa aproximação fantasiosa de criadores homens com uma suposta feminilidade, embora servisse para marcar um distanciamento em relação à ordem burguesa, ao ostentar uma espécie de sensibilidade distinta, era paralela à exclusão das mulheres reais da Literatura e das artes "respeitáveis", que continuavam existindo como ambientes marcadamente sexistas dentro do patriarcado burguês.

No mesmo momento em que Flaubert escrevia sua aclamada obra, a Europa vivia uma efervescência nos debates sobre cultura. Desde o final do século XVIII, transformações de ordem política e econômica, como a Revolução Industrial na Inglaterra e a Revolução Francesa, levaram a mudanças sociais que no campo da cultura se materializaram com o florescimento de uma literatura considerada "menor", voltada para as massas que começavam a ser alfabetizadas. Ganhava destaque, nesse momento, o público leitor feminino das novas classes médias, responsável pela expansão do consumo de pequenos livros de fantasia, aventura e paixão. Data sobretudo desta época a relação que percebemos ainda hoje entre as mulheres e os produtos massivos considerados menores. E é bastante sintomático que a obra de Flaubert, indicada até hoje como um dos principais livros do século XIX, narre a história de uma ávida leitora de romances açucarados, uma literatura descrita como de baixa qualidade (subjetiva, emocional, passiva)... E cujo desfecho trágico é associado à forma com que se entrega aos devaneios suscitados por essas narrativas.

Assim, para Huyssen (1996), a partir do olhar sobre Madame Bovary, podemos estabelecer uma série de pressupostos que vão se manter em maior ou menor grau nos debates sobre cultura nos séculos seguintes: de um lado, o homem produtor e consumidor de uma arte respeitável, que reivindica uma feminilidade instrumental quando esta é conveniente. De outro, a personagem, símbolo de todo um discurso intelectual que associava de maneira indelével o público feminino a diversos elementos que rebaixavam os objetos de seu interesse, considerando-os frívolos, banais, infantis, superficiais etc. 


\section{Considerações Finais}

A partir da discussão apresentada sobre a "TV de qualidade" e a construção e representação da masculinidade hegemônica na ficção seriada americana, não é estranho observar que a maior premiação da televisão americana, o Emmy Awards, reproduza também a lógica de aproximação do "masculino" com a noção de "qualidade". Uma forma de tornar mais tangível a presença masculina nas séries mais aclamadas e premiadas da televisão estadunidense contemporânea é tomar como referência as indicações e vitórias na categoria "melhor série dramática" do primetime (produções do horário nobre). De 2010 até 2017, foram 51 indicações (contando repetidamente aquelas que concorreram em mais de um ano). Dentre essas, apenas 11 vezes foram indicadas produções com uma personagem protagonista mulher (e, dentre esse número, estão apenas 6 séries $^{6}$, já que duas concorreram mais de uma vez). Dentre todas as indicadas nessa década, apenas uma é assinada exclusivamente por uma mulher; as duas outras com criadoras mulheres, concebidas colaborativamente, apresentam o nome dessas após o de um homem. No ano de 2017, The Handmaid's Tale (Hulu,2017-Presente) venceu a categoria de melhor série dramática nos Emmy Awards, tornando-se a segunda série da década com uma protagonista feminina (interpretada por Elisabeth Moss) a levar o prêmio, desde a vitória de Homeland $^{7}$ em 2012. Apesar disso, e do fato de a história ser baseada na obra literária de Margaret Atwood, foi um homem quem segurou a estatueta, por ocupar o cargo de showrunner da atração.

Da mesma forma que afirmamos, anteriormente, que não é aleatória a predominância de protagonistas homens e universos notadamente masculinos nas séries consideradas de prestígio nas últimas décadas, também podemos apontar que algumas mudanças de rumo recentes vividas pelo mercado não são fruto da coincidência. A incipiente (e bemvinda) diversificação dos sujeitos cujas vidas são narradas na ficção seriada televisiva contemporânea responde, certamente, a anseios que são compartilhados socialmente por um maior respeito a diferenças de gênero, de sexualidade e de raça. Séries com protagonistas femininas complexas, anti-heroínas, fortes, que escapam da tradicional

${ }^{6}$ As seis séries com protagonistas mulheres que já concorreram à categoria de melhor série dramática na premiação do Emmy até 2017 são: True Blood (HBO, 2008-2014); The Good Wife (CBS, 2009-2016); Homeland (Showtime, 2011-Presente); Orange is the new Black (Netflix, 2013-Presente); The Crown (Netflix, 2016-Presente); Westworld (HBO, 2016-Presente) e The Handmaid's tale (Hulu, 2017-Presente).

${ }^{7}$ Em 2012 Homeland foi escolhida como a melhor série dramática, e concorreu mais três vezes na categoria nos anos de 2013, 2015 e 2016. 
representação de gênero que costumava alinhar mulheres ao campo da simpatia e da docilidade (CASTELLANO; MEIMARIDIS, 2018), são resultado de demandas sociais articuladas em torno dos movimentos feministas, da mesma forma que uma maior preocupação com questões como representatividade étnica respondem não a benfazejos e desinteressados ímpetos de produtores, mas à pressão que o movimento negro, em suas múltiplas interseccionalidades, promovem.

Embora reconheçamos, portanto, que algumas mudanças começam a aparecer, acreditamos que ainda estamos longe da desejada equidade na representação de gênero (e também de raça, embora tenhamos concentrado nossa análise no primeiro paradigma). Nossa escolha por apontar a forte associação entre qualidade e o universo do masculino - o que se refere, como vimos, à narrativa, à produção e, também, ao público - teve como objetivo desnaturalizar essa vinculação. Nesse processo, chamamos a atenção para a negação do gênero em séries masculinas. Ou seja, narrativas centradas em personagens homens ganham um aspecto de universalidade, em contraposição a tramas protagonizadas por mulheres, facilmente rotuladas como séries femininas. Para além dessa questão, nos interessou, sobretudo, explicitar que o mesmo movimento que diferencia esses tipos de produção lança mão de critérios distintivos específicos, que além de classificar, o fazem a partir de uma forte hierarquização.

\section{Referências}

ALSOP, E. "The Unbearable Darkness of Prestige Television". The Atlantic. 8 de julho de 2015. Disponível em: https://www.theatlantic.com/entertainment/archive/2015/07/truedetective-game-of-thrones-bleak-television/397577/ Acesso em: 05 mar. 2018.

BAILEY, R. L. The content of network television prime-time special programming: 1948-1968. Journal of Broadcasting \& Electronic Media, v. 14, n. 3, p. 325-336, 1970.

BOURDIEU, P. A distinção: crítica social do julgamento. São Paulo/Porto Alegre: Edusp/Zouk, 2007.

BRASILIENSE; D.;ANSEL, Pedro. Representações da masculinidade viril contemporânea no programa popular da Rádio Cidade FM: Hora dos Perdidos. Revista Eletrônica de

Comunicação, Informação \& Inovação em Saúde, v. 10, n. 3, 2016. 
BREMBILLA, P.; TRALLI, L. With 22 Episodes a Year: Searching for Quality in US Network Television: the Cases of The Good Wife, Brooklyn Nine-Nine and Jane the Virgin. Comunicazioni sociali, v. 2, n. 2, p. 142-152, 2015.

CASTELlANO, Mayka; MEIMARIDIS, Melina. Netflix, discursos de distinção e os novos modelos de produção televisiva.Contemporanea: Revista de Comunicação e Cultura, v. 14, n. 2, p. 193-209, 2016.

CASTELLANO, Mayka; MEIMARIDIS, Melina. "Mulheres difíceis": A anti-heroína na ficção seriada televisiva americana. Revista FAMECOS: mídia, cultura e tecnologia, v. 25, n. 1, p. 1-23, 2018.

CONNELL, R. Masculinities. 2. ed. Berkeley and Los Angeles: University of California Press, 2005.

DAVIS, D. M. Portrayals of women in prime-time network television: Some demographic characteristics. Sex roles, v. 23, n. 5-6, p. 325-332, 1990.

DOW, B. J. "How Will You Make it on Your Own?": Television and Feminism Since 1970. In: Wasko, J. (ed), A Companion to Television, p. 379- 394, 2005.

FEASEY, R. Masculinity And Popular Television. Edinburgh: Edinburgh University Press Ltd, 2008 .

FEUER, J.; KERR, P; VAHIMAGI, T. MTM: Quality Television. British Film Institute, 1984.

FUREDI, F. Therapy culture. Cultivating vulnerability in an uncertain age. Londres: Routledge, 2004.

GITLIN, T. Inside prime time: With a new introduction. University of California Press, 1994.

HILMES, M. The bad object: Television in the American Academy. Cinema Journal, 2005, v. 45 n.1, p. 111-117, 2005.

HUYSSEN, A. Memórias do modernismo. Rio de Janeiro: Editora UFRJ, 1996.

LE BON, G. Psychologie des foules. Paris: Édition Félix Alcan, 1905. 
LOTZ, A. D. Redesigning women: Television after the network era. University of Illinois Press, 2006.

MAIO, B. La terza golden age della televisione, Cantalupo in Sabina, Rieti: EdizioniSabinae, 2009.

MAIO, B. Prefácio In. PÉREZ-GÓMEZ, Miguel Angel. (Ed.). Previously On. Interdisciplinary studies on TV series in the third golden age of television. Biblioteca de la Facultad de Comunicación de la Universidad de Sevilla, Sevilla, p.17-19, 2011.

MARTIN, B. Homens difíceis. São Paulo: Aleph, 2014.

MESSA, M. R. P. As mulheres só querem ser salvas: Sex and the City e o pós-feminismo. Dissertação de mestrado em Comunicação Social. PUC-RS, 2006.

MITTELL, J. Narrative complexity in contemporary American television. Velvet Light Trap, v.58, p. 29-40, 2006.

MCCABE, J.; AKASS, K. (Ed.). Quality TV: Contemporary American television and beyond. IB Tauris, 2007.

MUANIS, F. A pior televisão é melhor que nenhuma televisão. MATRIZes, v. 9, n. 1, p. 87-101, 2015 .

NEWMAN, M. Z. “Quality TV as Liberal TV.” Western Humanities Alliance journal, 70.3 Ed. Liu, Catherine, 2016.

RABINOVITZ, L. Sitcoms and single moms: Representations of feminism on American TV. Cinema Journal, v. 29, n. 1, p. 3-19, 1989.

RIBEIRO, D. O que é lugar de fala? Belo Horizonte: Letramento, 2017.

RICOEUR, P. Tempo e narrativa: Tomo 1. 1 ed. Campinas: Papirus, 1994.

ROSENBERG, A. "Love Proves that Prestigious Comedies have become as cliche as Anti-hero Dramas". The Washington Post. 23 de Fevereiro de 2016. Disponível em: https://www.washingtonpost.com/news/act-four/wp/2016/02/23/love-proves-that-prestigecomedies-have-become-as-cliche-as-anti-hero-dramas/?utm_term=.26d49933d308. Acesso em: 05 mar;. 2018. 
SPIGEL, L. The domestic economy of television viewing in postwar America, Critical Studies in Mass Communication, v.6, n.4, p. 337-354, 1989.

THOMPSON, R. J. Television's Second Golden Age: From Hill Street Blues to ER. Syracuse University Press, 1997.

THOMPSON, R. J. Preface. In In MCCABE, Janet; AKASS, Kim. (Ed.). Quality TV: Contemporary American television and beyond. IB Tauris, 2007, p.xvii-xx.

VIGARELlO, G.; CORBIN, Alain; COURTINE, Jean-Jacques. (org.). História da Virilidade. Petrópolis: Vozes, 2013.

${ }^{1}$ Professora do Programa de Pós-Graduação em Comunicação e do Departamento de Estudos Culturais e Mídia da Universidade Federal Fluminense. Doutora em Comunicação e Cultura pela Universidade Federal do Rio de Janeiro (PPGCOM ECOUFRJ), onde também realizou um pós-doutorado.E-mail: maykacastellano@gmail.com.

2 Doutoranda do Programa de Pós-Graduação em Comunicação da Universidade Federal Fluminense. Mestre pela mesma instituição. E-mail: melmaridis@hotmail.com.

${ }^{3}$ Mestrando do Programa de Pós-Graduação em Comunicação da Universidade Federal Fluminense. E-mail: gabrielferreirinho@gmail.com. 